\title{
Location selection of agricultural-residuals particleboard industry through group decision: The case study of northern Iran
}

\author{
Majid Azizi *, Mostafa Ramezanzadeh ** \\ * University of Tehran, \\ 16th Azar St., Enghelab Sq., Tehran, Iran \\ Professor, Faculty of Natural Resources \\ ** University of Tehran, \\ 16th Azar St., Enghelab Sq., Tehran, Iran \\ M. Sc., Faculty of Natural Resources
}

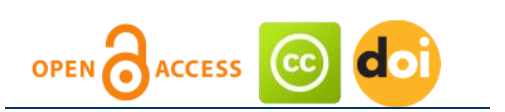

Article history:

Received: October, 2016

1st Revision: October,

2016

Accepted: October, 2016

\section{JEL classification: \\ Q16 \\ Q18}

DOI:

10.14254/jems.2016.1-1.2

\begin{abstract}
This paper presents a framework for locating agricultural-residuals particleboard industry in the northern provinces of Iran. Particleboard industry is the only Iranian wood and paper industry with an export potential and the use of agricultural residuals as the raw material can help with increasing the production in this industry, while reducing the damage to forest resources. The northern provinces of Iran are agricultural centers with ample amounts of agricultural residues. These provinces are, therefore, preferable to other provinces as the construction sites of particleboard plants. In the location selection model presented in this paper, the Analytical Hierarchy Process (AHP) method is used and the results indicate that the criterion of 'material and production' and the sub-criterion of 'reliability of supply' have the highest priorities, and that Golestan province is the best alternative.
\end{abstract}

Keywords: particleboard industry, location selection, Analytical Hierarchy Process, Iranian wood and paper industry.

\section{Introduction}

The problem of location is one of the most important concerns for many kind enterprises. Both the choice of criteria and the evaluation of possible alternatives are critical steps in the decision-making process of choosing the best location (Eichenberg et al., 2011). Location selection problem plays an important role in minimizing the cost and maximizing the use of resources for many companies. Location problems involve determining the location of one or more new facilities in one or more of several potential sites. Many potential criteria, such as investment cost, human resources, availability of materials, climate, etc., should be considered in selecting a particular plant location. Hence, plant location selection can be viewed as a multi criteria decision making (MCDM)

Corresponding author: Majid Azizi

E-mail: mazizi@ut.ac.ir

This open access article is distributed under a Creative Commons Attribution (CC-BY) 4.0 license. 
problem (Tavakkoli and Mousavi, 2011). Location theory has been an active area of research. Today, facility location is viewed as a substantial body of knowledge with a rich variety of models, methodologies and solution techniques that can be found in the literature pertaining to fields such as industrial engineering, operations research, operations management, urban economics and political science (Partovi, 2004).

This paper presents an application of the Analytic Hierarchic Process (AHP) technique for location selection of particleboard industry made of agricultural residuals as the only raw material in the northern provinces of Iran (Golestan, Mazandaran and Guilan). Figure 1 shows the position of these three provinces on the map of Iran.

Figure 1: The site of the three Alternatives on the map of Iran

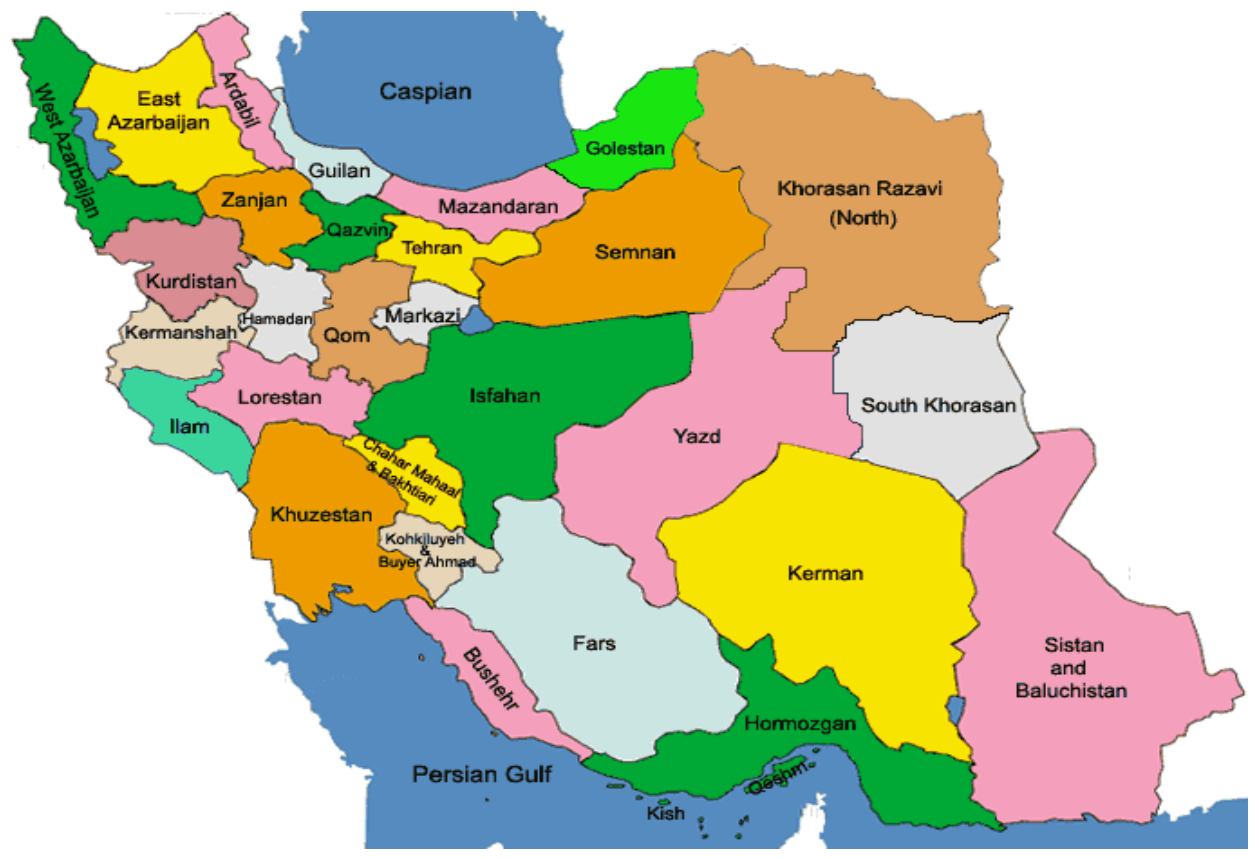

There are rich sources of agricultural residues in the north of the country and this reduces the cost of raw materials transportation. Also, to protect forest, the construction of new particleboard plants using agricultural residues in the north of Iran is economically justified. Table 1 shows the area under cultivation of crops in the three provinces and the total area in the country during the period of 2005-2010 (Ministry of Agriculture, 2012).

\begin{tabular}{|} 
Table 1: The area under cultivation of crops (ha) \\
\hline Year & $\begin{array}{c}\text { Golestan } \\
\text { province }\end{array}$ & $\begin{array}{c}\text { Mazandaran } \\
\text { province }\end{array}$ & Guilan province & Iran \\
\hline 2005 & 679678 & 392319 & 238873 & 13049944 \\
\hline 2006 & 690105 & 393236 & 23931 & 12961165 \\
\hline 2007 & 703592 & 356918 & 227278 & 13418241 \\
\hline 2008 & 625609 & 396483 & 208937 & 10150924 \\
\hline 2009 & 686759 & 461281 & 211607 & 12435203 \\
\hline 2010 & 695077 & 464068 & 206914 & 12729168 \\
\hline
\end{tabular}

Source: Ministry of Agriculture, 2012

Particleboard industry has the highest rate of wood consumption among the wood and paper industries in Iran. Currently, there are 20 active particleboard plants in the country, among which only Karun Chipboard factory uses agricultural residual as its raw material. Table 2 shows the latest statistics concerning production, import and export of particleboard (FA0, 2012). The table shows that the particleboard industry can supply the domestic demand and, the construction of new plants based on agricultural residuals as the raw material can pave the way for particleboard export. Moreover, replacing wood with agricultural residuals can reduce deforestation. Therefore, the location selection of the particleboard industry is of higher priority that other wood and paper industries. 


\section{Table 2: Production, imports and exports (cubic meters)}

\begin{tabular}{|c|c|c|c|}
\hline Year & Production & Imports & Exports \\
\hline 2005 & 700000 & 28000 & 6179 \\
\hline 2006 & 619000 & 9000 & 6179 \\
\hline 2007 & 682000 & 14000 & 6179 \\
\hline 2008 & 683000 & 54000 & 6179 \\
\hline 2009 & 609000 & 35000 & 6179 \\
\hline 2010 & 728000 & 33000 & 6179 \\
\hline
\end{tabular}

Source: FAO, 2012

Braglial and Gabbrielli (2012) used an effective Decision Support System (DSS) for site selection of a new paper mill in Italy. They used the AHP technique for this purpose. Tavakkoli and Mousavi (2011) studied the AHP for plant location selection. The aim of using the AHP is to give the weights of the selected criteria. Vali (2011) located floating paper industry in Golestan province of Iran by using AHP method based on profit to cost ratio. Hilmola et al., (2010) studied the location of biodiesel factory from wood and wood waste in Finland. Azizi et. al., (2006) studied the location selection of plywood and veneer industry in Iran by using AHP and fuzzy TOPSIS. Ramezanzadeh (2009) located MDF industry in the northern Iranian province of Mazandaran by using AHP method based on profit to cost ratio and selects the eastern part of the province as the best alternative. Walker (2006) studied the best location for sawmill industry. Burdulu et. al., (2003) located the furniture industry in Turkey by using AHP.

Hypothesis:

1- The criteria related to the raw material are of great importance.

2- The AHP can be useful and efficient for the new optimum location.

Objective:

To choose the best location for establishing particleboard plant using agricultural residues in the north of Iran.

\section{Methodology}

\subsection{Criteria selection}

After interviewing with wood and paper experts and studying past studies, restrictions that could be considered as effective factors in plants site selection were identified. The criteria are divided into five groups. The hierarchical tree of the study consists of five levels. Figure 2 shows the hierarchical structure criteria, sub-criteria and alternatives.

\section{Figure 2: Hierarchical tree for location selection of particleboard industry from agricultural} residuals in north of Iran
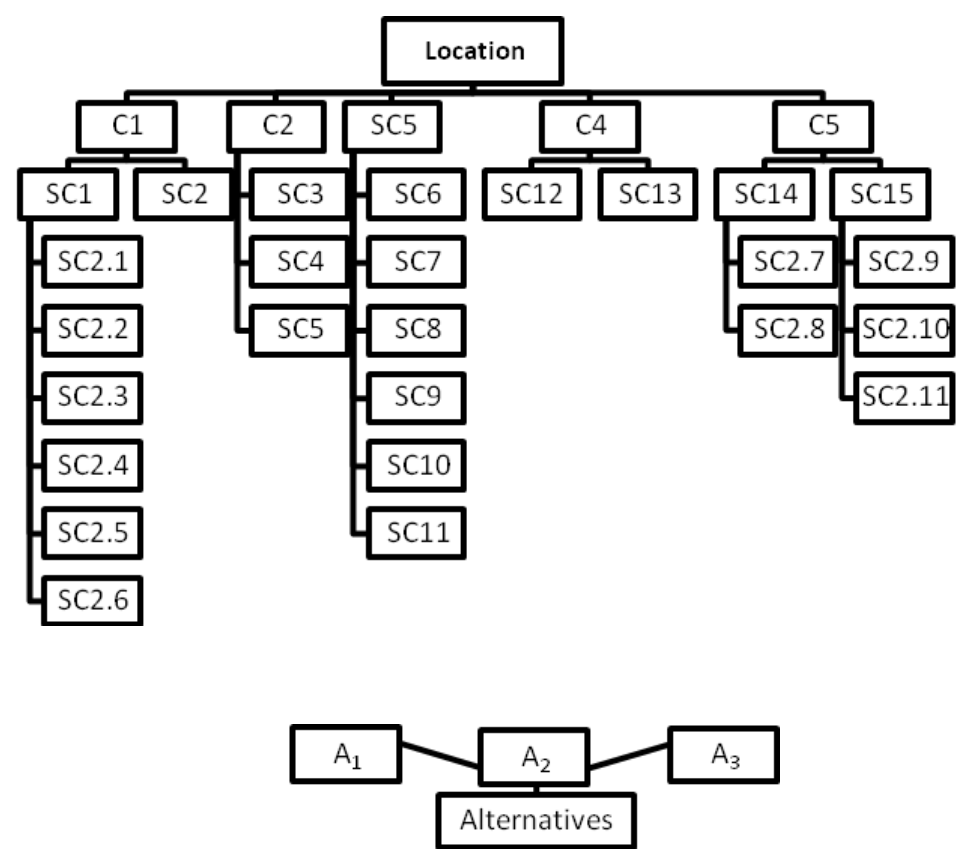
C1. Economical; C2. Human and Technical; C3. Infrastructure; C4. Laws and Regulations; C5. Materials and Products; SC1. Costs; SC2. Granted facilities; SC3. Education; SC4. Life facilities; SC5. Technical knowledge; SC6. Investment; SC7. Industrial history; SC8. Competitors; SC9 Transportation network; SC10. Energy; SC11. Status of agricultural mechanization; SC12. Distance range allowed of city for the construction of the factory; SC13. Tax rate; SC14. Final product; SC15. Raw materials; SC2.1. Land purchase cost; SC2.2. Labor cost; SC2.3. Fuel cost; SC2.4. Purchasing cost of raw material; SC2.5. Transportation cost of raw materials; SC2.6. Transportation cost of final product; SC2.7. Amount of sales and exports; SC2.8. Distance from market; SC2.9. Reliability of supply of raw materials; SC2.10. Distance of supply of raw materials; SC2.11. Quantity of raw materials; $A_{1}$. Golestan province; $A_{2}$. Mazandaran province; Аз. Guilan province.

\subsection{Analytical Hierarchy Process (AHP)}

Analytical Hierarchy Process (AHP) is a decision-aiding method developed by Saaty (AlHarbi, 1999). AHP is a mathematical method for analyzing complex decision problems under multiple criteria (Qureshi and Harrison, 2003). It has proven to be a powerful decision analysis technique in the area of Multi Criteria Decision Making (MCDM), and has been successfully applied to the tackling of MCDM problems (Volkova et al., 2010). AHP has been a tool at the hands of decision makers and researchers and it is the most widely used MCDM tools (Bhatt et al., 2010). AHP is a well-known technique that assumes a unidirectional hierarchical relationship among decision level and decomposes a decision problem into several levels in such a way that they form a hierarchy. In AHP, the top element of the hierarchy is the overall goal for the decision model. The hierarchy decomposes from the general to a more specific attribute until a level of manageable decision criteria is met. AHP is conceptually easy to use, but it is divisionally robust, so that it can handle the complexities of the real world problems. AHP can assist the analysts and decisionmakers to evaluate a problem in the form of a hierarchy of references through a series of pairwise comparisons of relative criteria. Relative weights are determined through pairwise comparison. The method can be applied by breaking down the unstructured complex scorecard problems into component parts. Hierarchical orders are then arranged by forming value tree structures. Subjective judgment on the relative importance of each part is represented by assigning numerical values. These values are selected in accordance to pairwise comparison scale. To evaluate the pairwise comparison there are some computer-based tools for individual as well as group-decision support (Phdungsilp and Wuttipornpun, 2011). The AHP allows group decision making, where group members can use their experience, values and knowledge to break down a problem into a hierarchy and solve it by the AHP steps (K.M. Al-S. Al-Harbi, 1999). 1) creating hierarchical tree, 2) pairwise comparing of research criteria and options, 3) operations for computing data, 4) sensitivity analysis, and 5) the level of non-adaptability (incompatibility), (D. Samari, et al., 2012). Steps 1 and 2 are made on the basis of the decision maker's knowledge and understanding of the problem and steps 3 to 5 are executed using an appropriate software, such as the Expert Choice (Peltola, et al., 2002).

AHP has been successfully applied to a diverse array of problems, with the calculation procedure as follows: Establishment of pair-wise comparison matrix $A$ let $C_{1}, C_{2}, \ldots, C_{n}$ denote the set of elements, while $a_{i j}$ represents a quantified judgment on a pair of elements $C_{i}$, and $C_{j}(\mathrm{C}$. R. Wu et al., 2007). After the hierarchy structuring, the pairwise comparison matrix is constructed for each level, where a nominal discrete scale from 1 to 9 is used for the evaluation (Table 3), (Ataei, 2005, Volkova et al., 2010, Al-Harbi, 1999).

Table 3: Scale of Relative Important

\begin{tabular}{|l|l|}
\hline \multicolumn{1}{|c|}{ Importance degree } & \multicolumn{1}{c|}{ Differentiation } \\
\hline 1 & Equal importance \\
\hline 3 & Moderate importance \\
\hline 5 & High importance \\
\hline 7 & Very high importance \\
\hline $2,4,6,8$ & Extreme importance \\
\hline
\end{tabular}


This yields an $n \times n$ matrix $A$ as follows (Wu, et al., 2007) : $C_{1}, C_{2}, \ldots, C_{n}$

$$
A=\left[a_{i j}\right]=\begin{gathered}
C_{1} \\
C_{2} \\
\vdots \\
C_{n}
\end{gathered}\left[\begin{array}{cccc}
1 & a_{12} & \cdots & a_{1 n} \\
1 / a_{12} & 1 & \cdots & a_{2 n} \\
\vdots & \vdots & \ddots & \vdots \\
1 / a_{1 n} & 1 / a_{2 n} & \cdots & 1
\end{array}\right]
$$

Where $a_{i j}=1$ and $a_{i j}=1 / a_{i j}, i, j=1,2, \ldots, n$. In matrix $A$, the problem becomes one of assigning to the $n$ elements $C_{1}, C_{2}, \ldots, C_{n}$ a set of numerical weights $w_{1}, w_{2}, \ldots, w_{n}$ that reflect the recorded judgments. If $A$ is a consistency matrix, the relations between weights $w_{i}$ and judgments $a_{i j}$ are simply given by $w_{i} / w_{j}=a_{i j}($ for $\mathrm{i}, \mathrm{j}=1,2, \ldots, n)$ and $C_{1}, C_{2}, \ldots, C_{n}$

$$
A=\begin{gathered}
C_{1} \\
C_{2} \\
\vdots \\
C_{n}
\end{gathered}\left[\begin{array}{cccc}
w_{1} / w_{1} & w_{1} / w_{2} & \cdots & w_{1} / w_{n} \\
w_{2} / w_{1} & w_{2} / w_{2} & \cdots & w_{2} / w_{n} \\
\vdots & \vdots & \ddots & \vdots \\
w_{n} / w_{1} & w_{n} / w_{2} & \cdots & w_{n} / w_{n}
\end{array}\right]
$$

Saaty suggested that the largest eigenvalue $\lambda_{\max }$ would be:

$$
\lambda_{\max }=\sum_{j=1}^{n} a_{i j} \frac{w_{j}}{w_{i}}
$$

If $A$ is a consistency matrix, eigenvector $X$ can be calculated:

$$
\left(A-\lambda_{\max } I\right) X=0
$$

Saaty proposed utilizing consistency index $(C I)$ and consistency ratio $(C R)$ to verify the consistency of the comparison matrix. $C I$ and $C R$ are defined as follows:

$$
\begin{gathered}
C I=\left(\lambda_{\max }-n\right) /(n-1) \\
C R=C I / R I
\end{gathered}
$$

Where $R I$ represents the average consistency index over numerous random entries of same order reciprocal matrices. If $C R \leq 0.1$, the estimate is accepted; otherwise, a new comparison matrix is solicited until $C R \leq 0.1$.

\subsection{Questionnaire planning}

After the hierarchical tree of criteria and sub-criteria was drawn, two questionnaires were designed. The first questionnaire was designed for paired comparisons between criteria and subcriteria and the weight and priority of these criteria were determined. The second questionnaire was designed to determine the weight and priority of the alternatives. For this purpose, the questionnaires were distributed among 10 experts $(2$ academic experts; 2 industries and mines organization experts; 2 natural resources experts; 2 experienced managers in the particleboard industry; and 2 agriculture experts). To determine the weight and priority of alternatives, AHP technique and Expert Choice software were used.

\section{Results}

The weight of criteria and sub-criteria (Table 4), geometric mean of criteria (Table 5) prioritization of criteria (Fig. 3) and prioritization of options (Fig. 4), calculated using Expert Choice software, is presented in this section. 


\section{Table 4: The final results of the weight of criteria and sub-criteria at different levels}

Economical $=0.199$

Granted facilities $=0.166$

Costs $=0.884$

Human resources $=\mathbf{0 . 0 7 3}$

Infrastructure $=0.249$

State laws $=0.037$

Materials and products $=$ 0.442
Purchasing land $=0.239$

Labor cost $=0.072$

Fuel cost $=0.143$

Purchasing agricultural residue $=.0044$

Transport cost for agricultural residue $=0.472$

Transport cost for the final product $=0.031$
Education $=0512$

Facilities of life $=0262$

Technical knowledge $=0226$

Attractive investment $=0.075$

Competitors $=0.066$

Industrial history $=0.054$

Transportation network $=0.126$

Energy $=0384$

Status of agricultural

mechanization $=0.296$

Tax rate $=0.750$

Distance range allowed $=0.250$

Raw material $=0.888$

Final product $=0.112$
Reliability of supply $=0.400$

Distance of supply $=0.190$

Quantity $=0.411$

Distance from market $=0.214$

Amount of sales and exports $=$ 0.786

\begin{tabular}{|l|c|c|c|c|}
\hline \multicolumn{1}{|c|}{ Table 5: Geometric mean of comparison paired matrices of criteria through AHP } \\
\hline $\begin{array}{c}\text { Human } \\
\text { resources }\end{array}$ & Infrastructure & State laws & $\begin{array}{c}\text { Materials and } \\
\text { Products }\end{array}$ \\
\hline Economical & 3.3227 & 1.31951 & 6.1531 & 2.70192 \\
\hline Human resources & & 4.53587 & 3.10369 & 6.15312 \\
\hline Infrastructure & & & 6.1531 & 2.16894 \\
\hline State laws & & & & 7.97484 \\
\hline
\end{tabular}

Blue numbers show "priority" and "reversed importance" of the criteria 
Figure 3: The final priority 22 sub-criteria affecting the particleboard industry site selection in northern of Iran

Quantity
Reliability of supply
Energy
Transport cost for agricultural residue
Supply distance
Status of agricultural mechanization
Purchasing land
Amount of Sale and export
Education
Transportation network
Tax rate
Fuel cost
Granted facilities
Facilities of life
Attract investment
Technical knowledge
Competitors
Labor cost
Industrial history
Distance from market
Distance range allowed
Purchasing agricultural residue
Transport cost for the final product

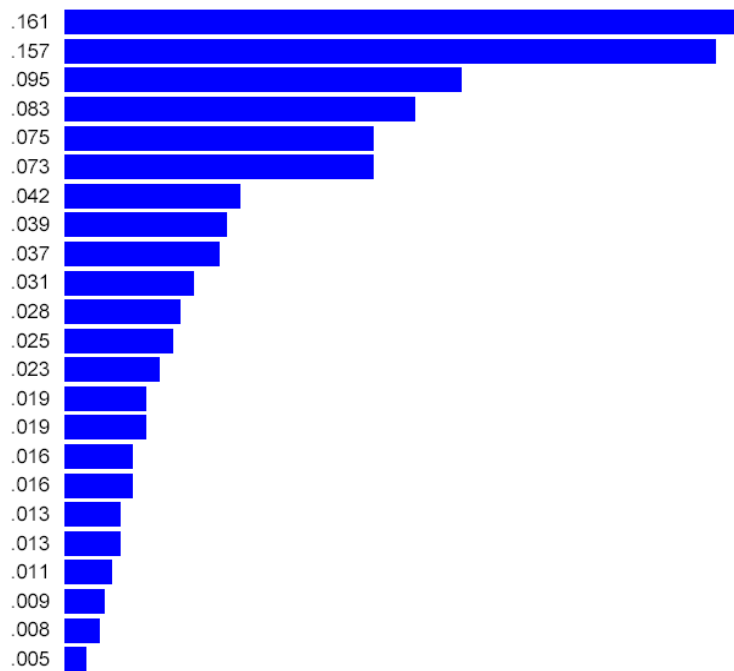

Figure 4: Prioritization of alternatives

Golestan
Mazandaran
Guilan

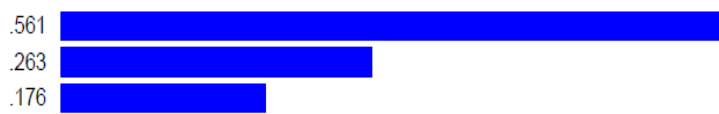

\section{Discussion and Conclusion}

The results show that the sub-criterion of quantity of agricultural residue and the criterion of materials and products have the highest priority. Reliability of supply, energy infrastructure, transporting cost of raw materials, distance of supply, the status of agricultural mechanization and land purchase cost are the top sub-criteria and Golestan province is chosen as the best option.

According to Table 1, the amount of raw materials is plenty in Golestan province. Therefore, reliability of supply of raw material in this province is more than other provinces. Also, because the volume to weight ratio of agricultural residue is more than wood, the cost of transporting raw material is extremely important. Because the amount of raw materials in Golestan province is more other provinces, the distance of supply of raw materials is the closest and cost of transporting of raw materials is lower than that of them. The source of raw materials is one of the most important factors influencing the selection of a plant site. Speaking of economics, it is beneficial to have a plant located close to the source of raw materials (Ataei, 2005). Walker (2006) considered that the amount of raw material within the region is important for a sawmill factory. Azizi et al., (2003) mentioned that purchase cost of raw material is the most important factor in locating plywood and veneer plants. They also concluded that the reliability of raw material supply is very important and it is the second priority. The transportation is the most important factor in selecting the aluminacement plant location site (Ataei, 2005).

Golestan province neighbors Turkmenistan. Turkmenistan supplies part of natural gas of Iran. So, the energy infrastructure in this province is better and more than other provinces. The criterion of energy is one of the effective criteria in location selection of an MDF plant (Azizi and Ramezanzade, 2011). Fuel and power supply is one of the most important factors influencing the selection of a plant site (Ataei, 2005).

Agricultural residue is the only raw material in this study. The status of agricultural mechanization is very important because it reduces costs. According to agricultural experts and field studies Golestan province is much better than other options. In a study, the mechanization status of Iran was considered and in comparison with other countries' experiences, some remedies were presented and it was mentioned that competent organizations should control the application of modern machines by farmers to prevent the decline of agricultural utilization caused by unsuitable technologies, while, increasing the utility by the appropriate ones (Lak, 2011). In a study, agriculture status is one of the effective criteria in location selection of floating paper plant in Golestan province of Iran (Vali, 2011). 
According to property experts, land price is low in Golestan province because Golestan province is farther from the capital city (Tehran) and is a less attractive tourist site than Guilan and Mazandaran provinces. Azizi et al., (2003) mentioned that the cost of land purchase is one of the important factors in locating plywood and veneer plants in Iran. Azizi and Ramezanzadeh (2011) concluded that the criterion of land purchase is one of the effective criteria in the selection site of MDF plants in Mazandaran Province of Iran.

\section{Sensitivity analysis}

To achieve stability and compatibility of the analysis, sensitivity analysis is applied. By increasing or decreasing one of the criteria, we found that the ratios of other criteria do not change (Azizi and Modarres, 2003).

The results of the application of Expert Choice software indicate that the criteria of economic and human resources have a sensitivity of changes in prioritizing alternatives and the criteria of infrastructure, government regulations and materials and products have no sensitivity (Table 6).

The results show that Golestan province has a better position and, therefore, it is selected as the best option. Also, according to the results of research, the hypotheses were confirmed.

\begin{tabular}{|} 
Table 6: Prioritization changes of alternatives and results of sensitivity analysis \\
\hline \multicolumn{1}{|c|}{ Criterion } & Basic weight & Changed weight & $\begin{array}{c}\text { Prioritization of } \\
\text { Alternative }\end{array}$ & $\begin{array}{c}\text { Number of } \\
\text { Sensitivity }\end{array}$ \\
\hline Economical & 0.199 & 0.618 & $\mathrm{~A} 1-\mathrm{A} 3-\mathrm{A} 2$ & 1 \\
\hline Human resources & 0.073 & 0.569 & $\mathrm{~A} 2-\mathrm{A} 1-\mathrm{A} 3$ & 1 \\
\hline Infrastructure & 0.249 & - & $\mathrm{A} 1-\mathrm{A} 2-\mathrm{A} 3$ & - \\
\hline State laws & 0.037 & - & $\mathrm{A} 1-\mathrm{A} 2-\mathrm{A} 3$ & - \\
\hline $\begin{array}{l}\text { Materials and } \\
\text { Products }\end{array}$ & 0.442 & - & $\mathrm{A} 1-\mathrm{A} 2-\mathrm{A} 3$ & - \\
\hline
\end{tabular}

\section{Acknowledgment}

The authors wish to thank all the experts for their participation in this research. We would also like to thank the University of Tehran, Tehran, Iran.

\section{Appendix A. Supplementary material}

Supplementary data associated with this article can be found, in the online version, at http://dx.doi.org/10.14254/jems.2016.1-1.2

\section{Funding}

The authors received no direct funding for this research.

\section{Citation information}

Azizi, M., \& Ramezanzadeh, M. (2016). Location selection of agricultural-residuals particleboard industry through group decision: The case study of northern Iran. Economics, Management and Sustainability, 1(1), 14-22. doi:10.14254/jems.2016.1-1.2.

\section{References}

Al-Harbi, K.M. Al-S. (1999). Application of the AHP in project management. International Journal of Project Management, 19, 19-27.

Ataei, M. (2005). Selection of Alumina-Cement Plant Location with Application of Multicriteria Estimation Method. Journal of Mining Science, 41(2), 185-194.

Azizi, M., Amiri, S., \& Faezipuor, M. (2003). Determination of Effective Criteria for Location Selection of Plywood and Veneer Units by AHP Method, Iranian J. Natural Resources, 55(4), 15.

Azizi, M., \& Modarres, M. (2003). Location selection of plywood and veneer plants by applying ANP and BOCR structure. Conference ISAHP Bali Indonesia.

Azizi, M., \& Ramezanzade, M. (2011). Location Selection for MDF Industry by Using Analytic Hierarchy Process Method, A Case Study: Mazandaran Province. Journal of Forest and Wood Products, 64(3), 261-281.

Bhatt, R., Macwan, J.E.M., Bhatt, D., \& Patel, V. (2010). Analytic Hierarchy Process Approach for Criteria Ranking of Sustainable Building Assessment: A Case Study, World Applied Sciences Journal, 8(7), 881-888. 
Braglia, M., \& Gabbrielli, R. (2012). A Decision Support System for locational analysis in paper industry. International Journal of Logistics Systems and Management, 11(1), 38-55. doi:10.1504/IJLSM.2012.044049.

Burdurlu, E., \& Ejder, E. (2003). Location choice for furniture industry firms by using Analytic Hierarchy Process (AHP) method, G.U., Journal of Science, 16(2), 5.

Eichenberg, T.R., Bandeira, D.L., \& Becker, J.L. (2011). Applying AHP to the process of determining the best combination of locations to a company's mobile operational units. Proceedings of the International Symposium on the Analytical Hierarchy Process.

Ghodsipuor, H. (2002). AHP. Industrial University of Amir Kabir.

Hilmola, O.P., Saranen, J., \& Padilha, F. (2010). Location criteria and strategic factors of biodiesel factory establishment in Finnish context. Lappeenranta University of Technology Department of Industrial Management. Kouvola Research Unit Research Report, 219.

Iranian Statistics Center. (2012). National Statistics Yearbook. Iranian Statistics Center, Tehran.

Lak, M.B. (2011). Estimation of Wheat Cultivation Mechanization Status in Iran. Asian Journal of Agricultural Sciences, 3(1), 51-55.

Partovi, F.Y. (2004). An analytic model for locating facilities strategically. The International Journal of Management Science, 34, 15.

Peltola, S., Torkkeli, M., \& Tuimala, J. (2002). Integrating GSS and AHP: Experiences from Benchmarking of Buyer-Supplier Relationships. Proceedings of the 35th Hawaii International Conference on System Sciences.

Phdungsilp, A., Wuttipornpun, T., 2011. Decision Support for the Selection of Electric Power Plants Generated from Renewable Sources, World Academy of Science, Engineering and Technology, 150-155.

Qureshi, M.E., \& Harrison, S.R. (2003). Application of the analytic hierarchy process to riparian revegetation policy options. Small-scale Forest Economics, Management and Policy, 2(3), 441458. doi:10.1007/s11842-003-0030-6.

Ramezanzadeh, M. (2009). Determination of Effective Criteria and Location Selection of MDF Industry in Mazandaran Province. Thesis of M.Sc., University of Tehran, 94.

Samari, D., Azadi, H., Zarafshani, K., Hosseininia, G., \& Witlox, F. (2012). Determining appropriate forestry extension model: Application of AHP in the Zagros area, Iran. Forest Policy and Economics, 15, 91-97.

Statistics agricultural crops. (2012). Ministry of Agriculture of Iran. Retrieved from: http://www.maj.ir.

Tavakkoli, M.R., \& Mousavi, S.M. (2011). An Integrated AHP-VIKOR Methodology for Plant Location Selection. IJE Transactions B: Applications, 24(2), 127-137.

Vali, M. (2011). Determination of Effective Criteria and Location Selection of Floating Paper Industry in Golestan Province. Thesis of M.Sc., University of Golestan, 78.

Volkova, A., Latosov, E., \& Siirde, A. (2010). Selection of the most appropriate regions for wood fuel based cogeneration plants using multi criteria decision analysis methods. International Journal of Energy, 4(2).

Walker, C.F.J. (2006). Primary Wood Processing. University of Canterbury, Christchurch, New Zealand.

Wu, C.R., Lin, C.T., \& Chen, H.C. (2007). Optimal selection of location for Taiwanese hospitals to ensure a competitive advantage by using the analytic hierarchy process and sensitivity analysis, Building and Environment, 42, 1431-1444.
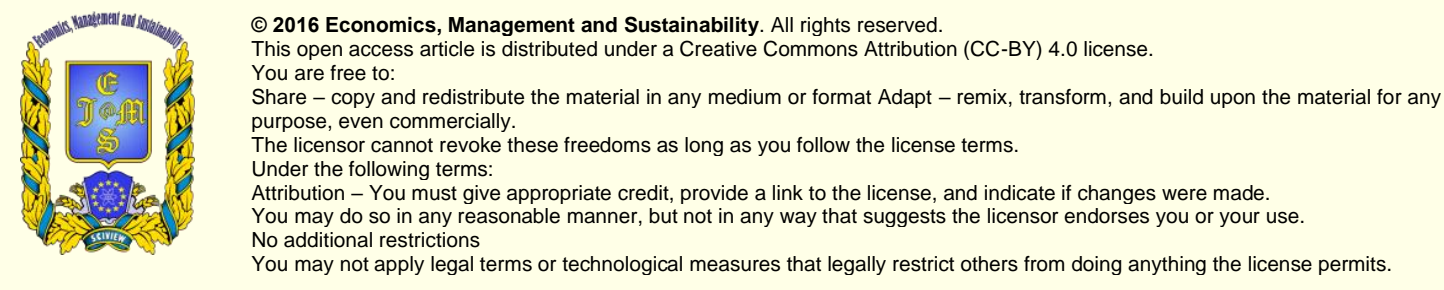

Share - copy and redistribute the material in any medium or format Adapt - remix, transform, and build upon the material for any purpose, even commercially.

The licensor cannot revoke these freedoms as long as you follow the license terms.

Under the following terms:

Attribution - You must give appropriate credit, provide a link to the license, and indicate if changes were made.

You may do so in any reasonable manner, but not in any way that suggests the licensor endorses you or your use.

No additional restrictions

You may not apply legal terms or technological measures that legally restrict others from doing anything the license permits.

Economics, Management and Sustainability (ISSN: 2520-6303) is published by Scientific Publishing House "CSR", Poland, EU and Scientific Publishing House "SciView", Ukraine

Publishing with JEMS ensures:

- Immediate, universal access to your article on publication

- High visibility and discoverability via the JEMS website

- Rapid publication

- Guaranteed legacy preservation of your article

- Discounts and waivers for authors in developing regions

- Discounts and waivers for authors in developing regions

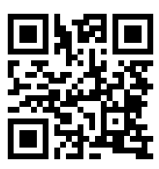

